\title{
Author Correction: Longitudinal assessment of tumor development using cancer avatars derived from genetically engineered pluripotent stem cells
}

\author{
Tomoyuki Koga (D, Isaac A. Chaim (D), Jorge A. Benitez (D), Sebastian Markmiller, Alison D. Parisian, \\ Robert F. Hevner, Kristen M. Turner, Florian M. Hessenauer, Matteo D’Antonio (1), Nam-phuong D. Nguyen, \\ Shahram Saberi, Jianhui Ma, Shunichiro Miki, Antonia D. Boyer, John Ravits, Kelly A. Frazer (1D, Vineet Bafna, \\ Clark C. Chen, Paul S. Mischel (1), Gene W. Yeo \& Frank B. Furnari (i)
}

Correction to: Nature Communications https://doi.org/10.1038/s41467-020-14312-1, published online 28 January 2020.

The original version of this Article contained an error in Fig. 1. The gel image in Fig. 1c was inadvertently taken from Supplementary Fig. 6 instead of Supplementary Fig. 1 that showed the original scan corresponding to Fig. 1c.

This has been corrected in both the PDF and HTML versions of the Article.

Published online: 20 April 2020

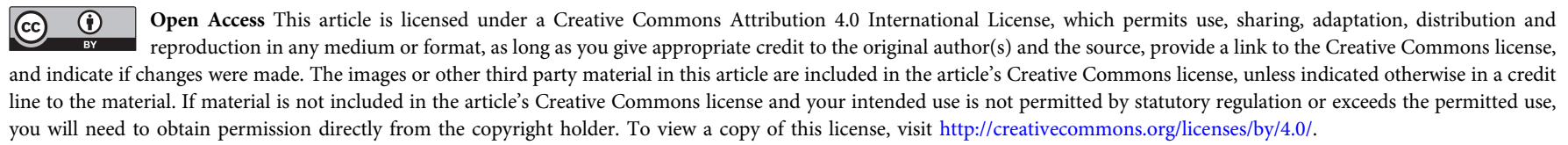

(C) The Author(s) 2020 